\title{
Prioritization of Crisis Management Practical Measures in the Field of Drought Using Views of Executive Managers \\ Jeiran Amiraslani ${ }^{1} \mathbb{D}$, Babak Omidvar ${ }^{2} \mathbb{D}$, Seyed Mohammad Shobeiri ${ }^{3}$
}

Date of submission: 22 Oct. 2018, Date of acceptance: 05 Feb. 2019

\begin{abstract}
INTRODUCTION: Drought is considered as a complex and creeping natural hazard associated with pervasive socio-economic and environmental impacts. Given the water reserves, per capita consumption, and average rainfall, Iran can be regarded as one of the countries facing the risk of lack of physical water resources and therefore proper management of drought in the country is an important issue. The main objective in the present study was to identify the dimensions gaining less attention in the context of executive drought management measures.

METHODS: This was an applied-developmental study performed with the field method along with documentary studies. The data collection tool and method, and data analysis method were a researcher-made questionnaire, structured interview, and Q methodology using factor analysis, respectively. The statistical population of the study consisted of 12 executives of the Forests Range and Watershed Management Organization, Deputy ABFA of Ministry of Energy, Agricultural Research, Education, and Extension Organization, Deputy Minister of Water and Soil of Ministry of Agricultural Jihad active in drought management executive actions in the country. To derive the questionnaire items using the expert opinion, 24 items on drought management performance measures were selected in four technical-structural, socio-economic, managerial, and environmental-climatic aspects and factor interpretation was performed on them.

FINDINGS: Based on the factor analysis of the results, the two technical-oriented and management-centered technical-oriented subjective models that both criticized the executive actions in the socio-economic dimension, were specified among the executives of the drought management field. Thus, according to the experts, most problems in the country in the field of drought management were in the socio-economic sector and most of the achievements in the technical-structural dimension.

CONCLUSION: The results of the viewpoints of the executive managers indicated that most of them considered health promotion in drought crisis as one of the achievements of the executive measures in this field in the country which can be used as a strength in future planning.
\end{abstract}

Original Article

Keywords: Drought; Crisis Management; Q Methodology; Executive's viewpoints; Executives

How to cite this article: Amiraslani J, Omidvar B, Shobeiri SM. Prioritization of Crisis Management Practical Measures in the Field of Drought Using Views of Executive Managers. Sci J Rescue Relief 2019; 11(1): 29-35.

\section{Introduction}

$\mathrm{T}$ oday, climate change is one of the major crises of life on Earth (1). According to the United Nations Convention to Combat Desertification (UNCCD), drought is a phenomenon that occurs naturally in case of a significant reduction in the rainfall rates from the recorded values, causing the disruption of the hydrological balance in a region. This phenomenon is along with a negative impact on

\footnotetext{
1- PhD Student, Environmental Education, Department of Environmental Education, Payame Noor University, Research Center for Emergency and Disaster Resilience, Red Crescent Society of the Islamic Republic of Iran, Tehran, Iran

2- PhD, Department of Environmental Engineering, School of Environment, College of Engineering, University of Tehran, Tehran, Iran

3- PhD, Department of Environmental Education, Payame Noor University, Tehran, Iran

Correspondence to: Babak Omidvar, Email: bomidvar@ut.ac.ir
} 
the ecosystem functioning, can reduce social, political, and economic stability, and can also increase vulnerability to other natural hazards such as floods $(2,3)$. In Iran, in the recent 50 years, the highest and most severe droughts took place during 1991 and also during the years 2001 to 2011. Eliminating the risk of drought is impossible; however, preparedness to face it can reduce the risk of drought becoming a crisis (4).

Drought is one of the climatic phenomena that causes huge damages each year to various sectors including water resources, environment, and human communities. In recent years, given the frequent droughts in Iran and the decline in water resources, their consequences have been emerged, needing more effort by planners and managers (4). Drought causes numerous problems in social, economic, environmental, and managerial aspects of society (5). Therefore, to properly manage this phenomenon, it is necessary to consider all the above aspects in a balanced way.

Studies have already been carried out in this field in Iran. Darijani et al. (6) identified drought crisis management strategies by expert views in this sector and categorized them into technicalirrigation, agronomic, institutional, and legal groups. The questionnaires related to the selection of the effective solutions were distributed among 39 experts in the province and the analytic hierarchy process (AHP) decision making model was utilized to rank the strategies.

Distributing questionnaires among 300 villagers and 30 natural hazard experts, Poortaheri et al. (7) stated that the socio-economic dimension was the most important aspect of vulnerability to drought.

Heydari Sareban and Bakhtiar (8) examined approaches to deal with drought from the perspective of Agricultural Jihad experts in Isfahan province, Iran. According to the results of this study, the most important strategies to cope with drought included economic diversification, subsidy allocations, capacity building, and training related to water management, local drought management, institutionalization, and enhancing self-efficacy among the villagers.

Zobeidi et al. (9) stated that using the Q methodology and factor analysis of data, there were two views of support and compromise among the 27 vegetable farmers and two passive fatalist and hopeless views among 19 wheat farmers. The study revealed that the individuals had different opinions about the causes, effects, and adaptation to climate change.

Motamedi and Baharlooee Bardshahi (10) presented a summary of the 10-step strategies of the World Meteorological Organization and the Global Water Partnership (GWP) Organization to manage and adapt to the drought phenomenon. These 10 steps included setting the national drought management policy commission, defining the goals of the national drought management policy, resolving conflicts among key water users with regard to transboundary consequences, preparing a list of data and financial resources and identifying at-risk groups, preparing drought preparedness plans including monitoring and alerting, identifying research and institutional requirements, integrating scientific and political aspects, building public awareness and consensus, and developing training programs for beneficiaries.

Esmaili and Khodadad (11) selected 344 individuals using the Cochran method to study the effects of drought management on economic improvement of rural farmers in Bonab, Iran, and randomly distributed the questionnaire among them. The results indicated the implementation of some drought risk management policies such as pressurized and drip irrigation and the use of drought resistant species.

The ignorance of managers and decision makers in some aspects and consequences of drought has always been a problem in drought management given the numerous problems arisen in society today, especially in the field of environment and socio-economic issues caused by drought.

Regarding the necessity of comprehensive implementation of drought management measures in order to reduce the crisis, the main purpose in the present study was to identify the dimensions that have been less considered in the implementation of drought management measures, in addition to determining the aspects with the highest challenges and problems in order to plan to eliminate them.

\section{Methods}

This study was performed with the field method along with the documentary studies. The data collection tool, data collection method, and data analysis method were a researcher-made questionnaire, structured interview, Q method using factor analysis, respectively. The statistical population of the study consisted of the executives active in the field of drought management. In this study, targeted sampling was employed to 
interview different individuals with different perspectives on the study topic. Other criteria for selecting experts for this study included a close relation with the study subject, high working experience, and having a key role in the implementation of crisis management practices.

A non-random method is employed in the sampling in Q studies, in which the statistical sample is smaller than other studies. In this type of study, large samples are not required, and even a statistical sample of between 5 and 10 individuals may represent different viewpoints of individuals (12). The statistical sample of the presented study consisted of 12 executives of the Forests, Range, and Watershed Management Organization, Deputy Abfa of ministry of energy, Agriculture Promotion, Training, and Development Organization, and Deputy Minister of Water and Soil of Ministry of Agricultural Jihad active in drought management executive actions in the country.

Based on the Q methodology, the practical steps of the study consisted of five basic steps. In this method, the researcher first acquires a deep understanding of the subject by the library studies and examining the research background. In the second step, the researcher's desired items are collected from the library studies selected in a collection called "discourse space". Gathering the discourse space is the basis on which the desired propositions are selected, then the required items of the questionnaire are selected from among the propositions according to the expert opinion and finally referred to the experts in the form of a standard Q questionnaire. In fact, the discourse space is a set of index items in the study area which can be prioritized and scored by the statistical sample (13). To create the discourse space of this study, two groups of resources were utilized, including: 1. Documentary study of library studies (review of theoretical foundations, research literature, and domestic and international research background by searching in books and articles) and examination of upstream documents including upstream documents of natural disaster management such as the Hugo Document and the documents on the drought management in the country and 2. Expert interviews. The third step comprised of summarizing and evaluating the contents of the discourse space. For this purpose, the texts of the articles, books, and interviews were converted into short, separate phrases so that a sample of expressions (items) could be selected from among them later. Donner (14) believed that there was no definite standard regarding the number of items in the $\mathrm{Q}$ method and it could vary between 20 and 50 items. In this step of the study, for item selection, 108 statements were selected based on the documentary study and a number of similar and duplicate statements were eliminated using the opinions of 10 experts and finally 24 items on drought crisis management practical measures were selected in four technicalstructural, socio-economic, managerial, and environmental-climatic aspects. To form the questionnaire, each item was written on a separate card, with the items listed in Table 1.

In the fourth step, the participants (executives) scored and categorized the items, which was actually the data collection stage. How to answer the questionnaire in the $\mathrm{Q}$ method was based on the scoring of the items from -4 to +4 , meaning that the items with the highest priority from the respondent's view were given a score of +4 , and the cards became less important as approaching -4 , so that the card with the least priority gained a score of -4 . In the answering process, scoring the items was conducted in both optional and compulsory ways (15). In this study, the compulsory scoring method was adopted (due to its higher accuracy). Because in the optional method, there is a high tendency to the intermediate and the no comment option, however this is not the case in the compulsory distribution method. In the fifth step, the collected data were analyzed and the extracted perspectives were interpreted (15). The factor analysis method was adopted for data analysis in this study. The factor analysis process consisted of two stages of extraction of viewpoints as the first stage; the basis for this classification was the variables correlation matrix. In the second stage, the optimal state of the viewpoints relative to each other was measured by the Varimax method, which is an orthogonal rotation.

In this study, the face validity was considered as the validity of the measuring instrument (questionnaire) and it was obtained using the experts' opinions. Face validity indicates whether the expressions address different aspects of the subject under investigation so that the selected statistical population can express its view by scoring the items. For this purpose, using the opinions of 10 experts in the face-to-face interviews, the validity of the study, i.e. the comprehensiveness of the selected terms, was confirmed. 
Table 1. Items selected regarding practical measures in the field of drought crisis management

\begin{tabular}{lcc} 
Dimension & Item & Item number \\
& Training and capacity building in the area of crisis management & 1 \\
Implementation of drought crisis management policies & 8 \\
Management & Health promotion in drought crisis & 10 \\
& Change from crisis management to risk management & 16 \\
Prioritization of managerial actions & 21 \\
Management of trans-boundary and common watersheds & 23 \\
Use of new technologies & 3 \\
Technical-structural & Development of infrastructure (Resilience) & 7 \\
& Productive water distribution & 9 \\
Creation of a databank & 13 \\
Performing watershed and aquifer plans & 14 \\
Implementation of monitoring and alert network & 18 \\
Moving towards sustainable development goals & 5 \\
Preservation and development of vegetation & 11 \\
Reducing environmental and climate damage & 12 \\
Using the achievements of environmental studies & 15 \\
Land preparation & 19 \\
Using weather-derived tools & 24 \\
Decline in migration rates & 2 \\
Considering psychological dimensions & Using media capacity & 22 \\
\hline
\end{tabular}

To assess the reliability of the questionnaire, the halving method and the Spearman-Brown relation (Relation 1) were employed (16). This method is used to determine the degree of internal consistency of a test. The correlation coefficient was utilized to evaluate the reliability of the whole test.

$$
\mathrm{Y}=2 \mathrm{R} /(1+\mathrm{R})
$$

Relation (1)

The $\mathrm{R}$ and $\mathrm{Y}$ values represent the correlation coefficient between the two halves of the questionnaire and the reliability coefficient of the whole questionnaire, respectively.

The reliability coefficient of the questionnaire was obtained as 0.93 based on the above relation. Since the reliability coefficient of higher than 0.85 was acceptable in the studies, the questionnaire was of an acceptable reliability (17).

The PQMethod software version 2016 was utilized to analyze the data collected from the responses of the drought management executives. The software output represented a factor analysis of the study data and finally, the managers' views were identified by interpreting the results of the software outputs. At the end of the factor analysis, i.e. extraction and rotation, the factor scores were obtained which were the basis for future interpretation of the results (13). In the present study, this interpretation reflected the current status of the drought management practices from the experts' point of view. Moreover, in each viewpoint, the dimensions and expressions with the highest and lowest priority were specified. Figure 1 demonstrates the study implementation steps.

\section{Findings}

Based on the questionnaire factor analysis, the participants with similar views were identified, thereby identifying two main perspectives with 6 participants each. All ABFA executives, two from the Forests, Range, and Watershed Management Organization, and one from the Department of Water and Soil of the Ministry of Agriculture Jihad had a similar view, called the first view. The second view included all the managers of the Disaster Management Organization, one from the Forests, Range, and Watershed Management Organization, and two from the Department of Water and Soil of the Ministry of Agriculture Jihad. Table 2 illustrates the views extracted after the factor analysis of the questionnaire.

After performing the factor analysis on all the views obtained from the questionnaire data, the factor scores of the views were calculated, and by 


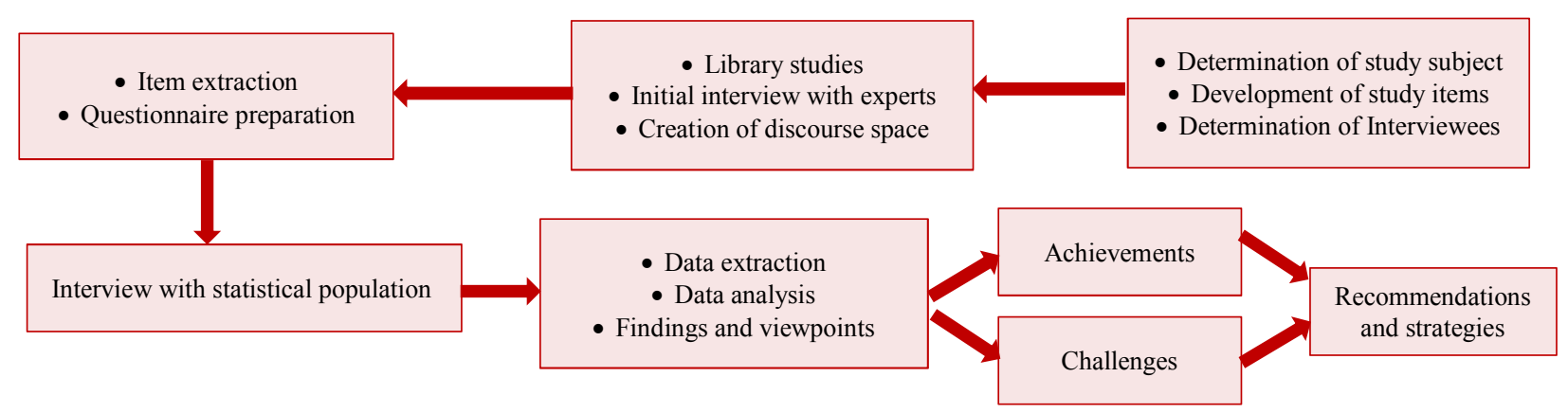

Figure 1. Study implementation detailed steps

normalizing the factor scores, a factor array was obtained which was an integer between -4 and +4 . Tables 3 and 4 illustrate the factor arrays obtained from the normalization of the factor scores of the managers.

Regarding the achievements of the drought crisis management and prioritizing them, among the 24 items in the first perspective according to Table 3, the top five priorities in terms of the achievements in the field of executive actions were respectively databank creation, infrastructure development, media capacity utilization, monitoring and alert network creation, and use of new technologies.

In the second view, based on Table 4, the top five priorities in the area of the achievements in the executive actions were respectively the databank creation, health promotion in a drought crisis, comprehensive training, and capacity building, prioritization of management measures, and use media capacities.

Between the above two views, consensus on the achievements of the area of implementation in accordance with Table 5 were the creation of a data bank, the use of media capacities, and the creation of a monitoring and alert network, two of which related to the technical-structural dimension and one to the socio-economic dimension.

In terms of the executive challenges of drought crisis management from the perspective of managers and prioritizing them according to the first view, based the factor score, the lowest achievements in this area were implementation of drought management policies, resolving local disputes, reducing migration due to drought, land preparation planning, and management of common and transboundry watersheds, respectively.

From the second view, the most challenging issues in the field of implementation were, respectively, the resolution of local disputes, the implementation of drought management policies, reducing migration due to drought, land preparation planning, and the management of common and transboundry watersheds. Among the two views, consensus on the most challenges in this area consisted of policy implementation, reduction of local drought disputes, reduction of drought migration rates, land preparation, and management of common and transboundry watersheds, respectively. Two, two, and one of these items were associated with the managerial dimension, socio-economic dimension, and environmentalclimate dimension, respectively.

Table 2. Views of the executives in the field of drought crisis management

\begin{tabular}{cccc} 
Participant number & Organization name & First factor & Second factor \\
1 & Department of Water and Soil & 0.5371 & 0.6634 \\
2 & Department of Water and Soil & 0.5488 & 0.6065 \\
3 & Department of Water and Soil & 0.7240 & 0.5135 \\
4 & Department of ABFA of Ministry of Energy & 0.8317 & 0.2334 \\
5 & Department of ABFA of Ministry of Energy & 0.7734 & 0.3706 \\
6 & Department of ABFA of Ministry of Energy & 0.7613 & 0.1952 \\
7 & Disaster Management Organization & 0.4284 & 0.8233 \\
8 & Disaster Management Organization & 0.2748 & 0.8767 \\
9 & Disaster Management Organization & 0.4753 & 0.7477 \\
10 & Forests Range and Watershed Management Organization & 0.5484 & 0.6093 \\
11 & Forests Range and Watershed Management Organization & 0.6986 & 0.5662 \\
12 & Forests Range and Watershed Management Organization & 0.6050 & 0.5297 \\
\hline
\end{tabular}


Table 3. Factor array of the first view of the managers

\begin{tabular}{|c|cc|ccccc|c|}
$-\mathbf{- 4}$ & $\mathbf{- 3}$ & $\mathbf{- 2}$ & $\mathbf{- 1}$ & $\mathbf{0}$ & $\mathbf{+ 1}$ & $\mathbf{+ 2}$ & $\mathbf{+ 3}$ & $\mathbf{+ 4}$ \\
\hline 8 & 2 & 19 & 11 & 5 & 10 & 18 & 6 & 13 \\
& 20 & 22 & 15 & 14 & 12 & 21 & 7 & \\
& & 23 & 4 & 16 & 17 & 3 & & \\
& & & 1 & 24 & 9 & & & \\
\hline
\end{tabular}

According to the factor scores of each of the items according to the executives, as Table 6, it was revealed that in this area, the highest and lowest attention was paid to the technicalstructural dimension and the socio-economic dimension, respectively.

Table 4. Factor array of the first view of the managers

\begin{tabular}{c|c|c|cc|cccc}
$\mathbf{- 4}$ & $\mathbf{- 3}$ & $\mathbf{- 2}$ & $\mathbf{- 1}$ & $\mathbf{0}$ & $\mathbf{+ 1}$ & $\mathbf{+ 2}$ & $\mathbf{+ 3}$ & $\mathbf{+ 4}$ \\
\hline 20 & 2 & 22 & 11 & 24 & 17 & 6 & 10 & 13 \\
& 8 & 23 & 5 & 16 & 12 & 18 & 1 & \\
& & 19 & 9 & 14 & 15 & 21 & & \\
& & & 7 & 3 & 4 & & & \\
\hline
\end{tabular}

\section{Conclusion}

Regarding the executive measures based on the factor analysis on the results, two views could be identified among the managers. The first view indicated managers who emphasized the technical-structural dimension of the executive measures for drought management in Iran, and because of this emphasis, it was called a technical viewpoint. The second view showed the managers' emphasis on the technical-structural aspects in the first place and the management in the second place. Therefore, this viewpoint was named as the management-centered technical view. The recognition of these two perspectives among the executives of this field indicated the tendency of these managers towards constructive solutions to cope with the drought phenomenon.

The results of the factor analysis showed that both groups of managers included technicaloriented managers and management-centered technical-oriented managers critical of executive measures taken in the socio-economic dimension. This means that both groups of managers allocated the lowest scores on the socio-economic aspects.
Given the ability of the Q method to represent different points of view and since the scores assigned to the items were capable of displaying the strengths and weaknesses in each of the four dimensions studied in detail, the results can be used a basis to provide a solution to achieve the desired situation. Based on the responses given regarding the ignorance of the socio-economic dimension of drought management, the findings of this study are in full agreement with those of the study by Poortaheri et al. (7) who considered the socio-economic dimension as the most important aspect of the drought vulnerability. The results were also in line with those of the study by Heydari Sareban and Bakhtiar (8) who stated that the recognition of the socio-economic conditions of society was essential for proper management of drought. Furthermore, based on the responses of managers, the highest achievements have been made in the technical-structural dimension in the country. This was consistent with the study by Esmaili and Khodadad (11) on the use of pressurized and drip irrigation methods and other technical-structural approaches to improve the current economic situation of farmers.

The analysis of the results obtained from the viewpoints of the executives showed that all managers with the second view (including managers of the crisis management organization) expressed health promotion in drought crisis as one of the achievements of the executive actions in this field in the country which can be used as a strength in future planning.

Finally, the following suggestions are made to overcome the challenges of the drought crisis management:

- Developing a comprehensive drought management plan recognizing the socio-economic conditions of Iran in order to properly implement drought management policies and prevent partiality and parallelism as well as consideration of land use planning capacities.

- Paying attention to the socio-economic dimension and consideration of the environmentalclimate dimension in the agenda of the executives

Table 5. Managers' views consensus on drought management achievements

\begin{tabular}{|lcc|c|} 
Rank & Item & View factor score & View factor score \\
\hline 1 & Creation of a databank & 2.054 & 2.034 \\
2 & Using media capacities & 1.011 & 0.981 \\
3 & Monitoring and alert network implementation & 0.866 & 0.955 \\
\hline
\end{tabular}


Table 6. Factor score of the dimensions investigated based on the managers' views

\begin{tabular}{|l|c|c|}
\hline Dimension & $\begin{array}{c}\text { First view } \\
\text { factor score }\end{array}$ & $\begin{array}{c}\text { Second view } \\
\text { factor score }\end{array}$ \\
\hline $\begin{array}{l}\text { Technical-structural } \\
\text { dimension }\end{array}$ & 0.9663 & 0.3425 \\
$\begin{array}{l}\text { Managerial } \\
\text { dimension }\end{array}$ & -0.248 & 0.111 \\
$\begin{array}{l}\text { Environmental- } \\
\text { climatic dimension }\end{array}$ & -0.2575 & -0.121 \\
$\begin{array}{l}\text { Economic-social } \\
\text { dimension }\end{array}$ & -0.4612 & -0.3325 \\
\hline
\end{tabular}

- Training managers looking at the most important challenges mentioned in the executive fields through planning future trainings focusing on the educational needs of the target community

- Adopting necessary measures and raising awareness to change the views of managers to non-structural management.

- Developing strategies for managing local disputes caused by droughts and common and transboundry watersheds.

- Updating existing drought management status studies periodically to continuously monitor achievements and challenges in this area.

\section{Acknowledgments}

\section{None}

\section{Conflict of Interests}

Authors have no conflict of interests.

\section{References}

1. Romm J. Climate change: What everyone needs to know. Oxford, UK: Oxford University Press; 2015.

2. Mishra AK, Singh VP. A review of drought concepts. J Hydrol 2010; 391(1): 202-16.

3. United Nations Convention to Combat Desertification (UNCCD). Land and drought (Online). (cited 2019); Available from: URL: https://www.unccd.int/issues/land-and-drought

4. Doostan R. Analysis of the Iran droughts in the past half century. Journal of Climate Research 2016; 6(23-24): 106-7. [In Persian]

5. Walker M, Thers A. Drought as a natural hazard. Drought: A Global Assessment 1996; 1(5): 3-18.
6. Darijani A, Shah Hosseini Dastjerdi S, Shahnooshi N, Kohansal MR. risk strategic management pattern: Case study Golestan province. Proceeding of the $2^{\text {nd }}$ International Conference on Plant, Water, oil and Weather Modeling; 2013 May 8-9; Kerman, Iran. [In Persian]

7. Poortaheri M, Eftekhari AR, Kazemi N. The role of drought risk management approach in reducing social-economic vulnerability of farmers and rural regions case study: Sulduz rural district, Azarbaijan Gharbi. Journal of Rural Research 2013; 4(1): 7-13. [In Persian]

8. Heydari Sareban V, Bakhtiar S. Exploring Drought Facing Solution in Rural Area: Case Study Isfahan Province. Journal of Geographic and Environmental Research 2015; 15: 19-34. [In Persian]

9. Zobeidi $T$, Yazdanpanah $M$, Forouzani $M$, Khosravipour B. Typology of wheat and vegetable farmers' perception towards climate change through of q-methodology. Journal of Rural Research 2016; 7(2): 374-91. [In Persian]

10. Motamedi A, Baharlooee Bardshahi D. Integrated drought management program. Journal of Water and Sustainable Development 2017; 4(1): 117-24. [In Persian].

11. Esmaili F, Khodad M. Drought Risk Management and its Impact on Economic Improvement of Rural Farmers; A Case Study on Bonab Township. Journal of Applied Studies in Management and Development Science 2018; 2(2): 1-10. [In Persian]

12. Brown SR. Q technique and method: Principles and procedures. In: Berry WD, Lewis-Beck MS, Editors. New Tools for Social Scientists: Advances and Applications in Research Methods. Thousand Oaks, CA: Sage Publications; 1986. p. 57-76.

13. De Graaf G. Q methodology: A sneak preview (Online). (cited 2005); Available from: URL: http://qmethod.org/articles/vanExel.pdf

14. Donner JC. Using Q-sorts in participatory processes: An introduction to the methodology. Social Development Papers 2001; 36: 24-49.

15. Khoshgooyanfard AR. Q Methodology. Tehran, Iran: IRIB Publications; 2007. [In Persian].

16. Kaplan RM, Saccuzzo DP. Psychological testing: Principles, applications, and issues. Boston, MA: Wadsworth Cengage Learning; 2009.

17. Moree W. Q-Methodology explained by comparing q-sort survey with conventional $r$-sample survey and relating factor analysis described. Civil Eng Res J 1(2) 2017; 1(2): 555560. 